\title{
LA CASA BELLA \\ Estética, Identidad, Poder y Distorsión de Metas en la Vivienda Social
}

\section{Víctor Saúl Pelli}

Arquitecto. Investigador Principal del CONICET. Director del Instituto de Investigación y Desarrollo en Vivienda (IIDVi) y Profesor de «Gestión y Desarrollo de la Vivienda Popular» en la Facultad de Arquitectura y Urbanismo de la UNNE.

Cuaderno Urbano N 4, pp. 183-202, Resistencia, Argentina, Diciembre 2004 


\section{CUADERNQ}

184

La Casa Bella. Estética, Identidad, Poder y Distorsión de Metas en la Vivienda Social

Villa Rotonda. AndreaPalladio. Foto:Mary Ann Sullivan.

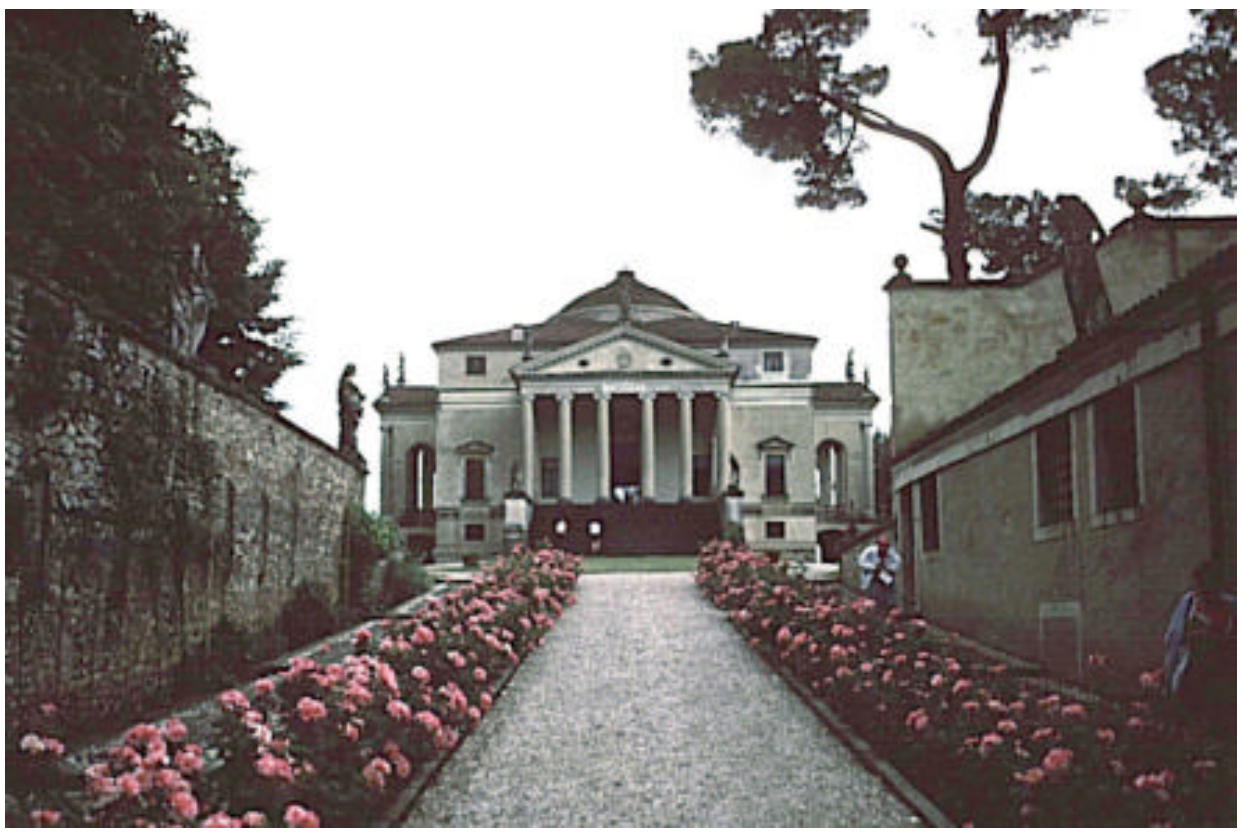

La confrontación de las orientaciones estéticas de los principales personajes de la gestión de la vivienda social: los habitantes, los arquitectos, los funcionarios y "el público", y el conflicto no declarado de poder entre todos ellos en torno a este tema, son un factor latente y poderoso de distorsión del desarrollo, del sentido y del éxito de la acción habitacional y, consiguientemente, de frustración del logro de la buena vivienda. 


\section{Víctor Saúl Pelli}

La Casa Bella. Estética, Identidad, Poder y Distorsión de Metas en la Vivienda Social

\section{LA ESTÉTICA, LA IDENTIDAD Y LA CASA DE LA GENTE}

La casa, del mismo modo que la ropa, el arreglo personal, la forma de hablar y moverse, el vehículo y la ubicación en la ciudad, constituye uno de los medios de expresión de la identidad de su "portador", y también de sus inclinaciones estéticas. El habitante de cualquier condición socioeconómica, si tiene posibilidad de incidir en la conformación externa e interna de su casa (incluida su ubicación urbana), trata de lograr un escenario en el que le sea grato verse y moverse en su vida doméstica y vecinal, y también intenta que su casa exprese ante los vecinos, ante las relaciones directas, ante la sociedad en general, y también ante él mismo, la identidad que quiere mostrar: la vivienda debe informar sobre lo qué́les, y con mayor frecuencia sobre lo que él cree que es, o sobre lo que quiere que los demás piensen que es. Salvo aberraciones, está en su derecho, pues se trata de una necesidad.

El habitante de una vivienda convencional de plan público, que no eligió su casa, diseñada por alguien a quien no conoce y que no lo conoce a él, no puede contar inicialmente con ese medio de expresión y satisfacción, pero con el tiempo busca el camino y las formas de sentirse a gusto y de expresar su identidad, con los recursos de ornamentación y terminación a su alcance; incluso, a veces, modificando la estructura misma de la casa, muchas veces ante el desdén o el malestar de los otros actores: el arquitecto, la "opinión pública", los vecinos inmediatos o el municipio.

\section{LAS DIFERENTES ESTÉTICAS DE LOS DIFERENTES SECTORES SOCIALES}

Aquí se dará por aceptado que puede haber diferencias importantes de orientación estética entre los distintos compartimientos de una misma sociedad: clases, edades, gremios, cofradías. El gusto auténtico que, por ejemplo, cultivan algunos sectores sociales por escuchar música de bailantas y por compartirla en alto volumen con los vecinos, es diferente del de los que disfrutan de otros géneros musicales y de otras formas de escuchar y compartir, o de los que gozan del silencio propio y del de los demás. Este es un registro cotidiano sobre el que no cabe, creo, discusión. 


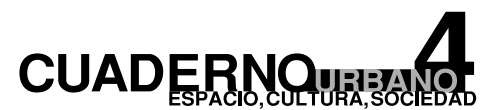

La Casa Bella. Estética, Identidad, Poder y Distorsión de Metas en la Vivienda Social

1- Barreto, M. A. 2000 .

\section{$\underline{\text { EL "SONIDO" DE LA VIVIENDA }}$}

De manera más silenciosa, la casa y el barrio presentan diferentes modos preferidos de expresión según los sectores sociales a que pertenecen los habitantes ${ }^{1}$ y según las tendencias culturales a las que ellos adhieren, consciente o inconscientemente. También entrando en armonía o conflicto con otros sectores, o simplemente con los vecinos, y también abriendo polémica sobre la medida de respeto, social e institucional, que merece la diversidad de orientaciones.

\section{ESTÉTICA Y PRIORIDADES}

Pero la vivienda también es una evidencia del lugar que las necesidades de satisfacción estética y de expresión de identidad ocupan en la lista de prioridades de cada habitante, al confrontarse con sus limitaciones de recursos, de tiempo y de dedicación, o con su propia escala de valores. Esto varía, desde luego, de habitante a habitante. Para algunos suele ser prioritario presentar una fachada -o simplemente la puerta de entrada-con apariencias de lujo antes de haber completado comodidades básicas en el interior. Para otros las cosas son a la inversa y el perfeccionamiento de determinados aspectos funcionales (suficientes dormitorios, instalación de agua caliente, aislamiento térmico básico) es prioritario en relación con la apariencia.

La apariencia miserable, "antiestética", de una vivienda modesta y "sin terminar", no necesariamente implica insensibilidad ni ausencia de exigencias estéticas de parte de sus habitantes. Puede estar siendo el resultado de una rigurosa asignación de prioridades dentro de un panorama general de necesidades elementales de supervivencia y reproducción insatisfechas, con un presupuesto extremadamente insuficiente. Aquí hay que señalar que este producto "imperfecto", típico del proceso de solución encarado por el habitante de recursos escasos y sin ninguna ayuda institucional, aparece también como un rasgo típico de los modelos de gestión habitacional institucional basados en criterios de resolución extendida de 


\section{Víctor Saúl Pelli}

La Casa Bella. Estética, Identidad, Poder y Distorsión de Metas en la Vivienda Social

las necesidades básicas, progresividad y participación. De estos modelos de gestión y de estos criterios se hablará más adelante, colocándolos en el eje de referencia de este trabajo.

\section{EL ARQUITECTO Y LA BELLA FORMA: LA REALIZACIÓN PROFESIONAL Y LA MI- SIÓN SOCIAL}

El arquitecto es el profesional capacitado y autorizado en el consenso social para la definición estética. Una vez que una persona se ha formado en esta disciplina, su vida profesional y en buena medida también su vida personal giran en torno a la temática estética de manera dominante. Es cierto que no todos los arquitectos están en los hechos trabajando en el campo de la creación formal, pero en su gran mayoría coinciden en adjudicarle la mayor jerarquía al tema, estén o no dedicados personalmente a él: el edificio o el sector urbano proyectado por el arquitecto debe ser bello. La bella forma ${ }^{2}$. Este núcleo, tan fuerte y dominante, es al mismo tiempo impreciso y cambiante ${ }^{3}$ : qué es la bella forma y quién lo dictamina; esto es tema de permanente debate, no sólo entre los arquitectos sino dentro del mismo arquitecto. Este estado constante de replanteo, en determinado marco, merece reconocerse como necesario y provechoso para la evolución de la disciplina y del tejido cultural en general, pero exige un tratamiento particularmente cuidadoso y una cierta rectificación de las reglas de juego habituales en escenarios como el que nos interesa aquí.

El Movimiento Moderno de arquitectura y su doctrina tendieron a comprometer al arquitecto en una misión educadora, casi evangelizadora, entendida como la misión de imponer la estética del Movimiento al usuario y también a la ciudad o al paisaje. Esta actitud goza aún de buena resonancia en la profesión, aunque hoy con fundamentos menos solemnes y con un repertorio más amplio y flexible que el del Movimiento Moderno. Hoy muchos más arquitectos están más predispuestos a admitir las preferencias estéticas del comitenteusuario y también las necesidades de diálogo y de negociación entre la obra arquitectónica y la ciudad, la cultura local y las condiciones ambientales. Pero si queremos hablar de la estética del habitante de los sectores populares, esta articulación parece más problemáti-
2- Decidí limitarme aquí al término "bello-bella" con un criterio de economía de expresión, dando por reconocido que el discurso sobre estética incluye el tratamiento de lo "no bello", e incluso de lo monstruoso, como objeto o como meta de la actividad creadora en el plano estético.

3- Hay muchos ejemplos en arquitectura de esta movilidade indeterminación de lo que es la bella forma. Entre ellos el del rechazo de la Torre Eiffel, como adefesio, por los intelectuales y artistas de su épocay su ciudad. En qué momento y por qué mecanismos la torre pasó a ser universalmente bella, en la medida en que lo ha sido durante todo el siglo $\chi \chi$, son preguntas de difícil respuesta, como también lo serán, sin duda, las preguntas sobre en qué momento y por qué motivos la torre pasará a perder impacto y significación o a ser directamente ignorada por las nuevas generaciones dentro del torrente de atracciones que traen los nuevos tiempos. Más cerca, en nuestras ciudades argentinas, el proceso que sufrieron las casas sobrevivientes del período colonial, con remodelaciones a la italiana, o a la francesa, y luego "modernas", y las que fueron revalorizadas más recientemente con su forma original o con la de alguna de las etapas intermedias. Lo que importa aquí es señalar la fragilidad y relatividad del 


\section{CUADERNQR}

La Casa Bella. Estética, Identidad, Poder y Distorsión de Metas en la Vivienda Social

consenso sobre lo que es bello (y correlativamente sobre los que es monstruoso), demasiado volátil como para pretender "imponer belleza" desde un estrato social al otro: desde el arquitecto, en especial, al destinatario de planes de vivienda social, que puede estar transitando $y$ asimilando otras etapas o cultivando otras tendencias.

4- Esta lista indicativa, que armé como ejemplo, puede no ser más que una visión desde afuera, pobre y

estereotipada, de un mundo de placeres sensoriales que seguramente es más rico, variado y significativo merecedor de mayor respeto, casi no

habría que decirlo, y también merecedor de ser explorado por los profesionales, de la mano del habitante, principal experto en saber quées lo que le gusta y quées lo que no le gusta; qué es lo que lo hace sentiren su lugary quées lo que lo hace sentir un extraño. ca: icómo un arquitecto comprometido con la búsqueda de los efectos formales y espaciales más evolucionados y refinados, y consagrado a la sintonía con las corrientes mundiales en boga, o más elementalmente, a la dura competencia con sus colegas y a la confrontación con la crítica profesional, puede disponerse a "firmar" una vivienda que expresa las expectativas de un habitante que navega en una estética amasada con cumbias, flores de plástico y cortinas del mismo material, imágenes religiosas de modesta factura, fotos de astros del fútbol o de la televisión, enanitos y cisnes de jardín, almanaques y el banderín del club ${ }^{4}$ ?

La firma (entendida aquí como marca de autoría artística) y también la foto (más precisamente la foto para publicar, tomada a veces casi como una meta en sí misma de la labor profesional), son símbolos de este punto de conflicto. Para el arquitecto que se dispone a internarse en el campo de las necesidades populares se hace indispensable replantearse a fondo estos dos temas para allanar los obstáculos subjetivos, muy duros, que se interponen entre su capacidad de trabajo y de aporte, por un lado, y las formas adecuadas de práctica profesional basadas en una relación personalizada y horizontal con el habitante ubicado en una diferente clave cultural, por otro.

La vivienda que debe expresar, o al menos tender a expresar, dentro de su misión básica de satisfacer necesidades, lo que el habitante es, o lo que quiere que los demás piensen que él es, se confronta en los hechos con la vivienda concebida para expresar lo que el arquitecto es, o lo que quiere que los demás piensen que él es, qué piensa y qué sabe hacer. El conflicto se dirime según la medida del poder de decisión que cada parte tiene sobre la obra y también en la medida en que cada una decide respetar el derecho o las aspiraciones del otro; es decir en la medida en que cada una decide ceder, mal o bien, su cuota de poder, cualquiera que esta sea.

\section{LA ESTÉTICA DE LOS SECTORES SOCIALES CONSOLIDADOS}

Quizá desde una aproximación fina es discutible esta pretensión de agrupar y englobar bajo un solo rótulo una diversidad tan amplia como la que sugiere este subtítulo, pero aquí no se intenta un análisis específico y especializado, sino registrar los efectos de actitudes que, 


\section{Víctor Saúl Pelli}

La Casa Bella. Estética, Identidad, Poder y Distorsión de Metas en la Vivienda Social

más desde la experiencia práctica en el "mundo" de la vivienda que desde la teoría, y del intercambio con los colegas que también actúan en ese "mundo", puedo afirmar que tienen constante presencia en la discusión de los modelos de gestión habitacional y de sus resultados: La opinión un funcionario, o dirigente, o periodista, o gobernante, o del "público" en general, puede llegar a ser el origen de la descalificación de un proyecto e incluso de una operatoria, sólo basándose en el rechazo que produce, a partir de códigos y valores propios de los sectores socialmente consolidados, el aspecto de los trabajos terminados; esto, casi sin excepción, sin tener en cuenta los intereses, la apreciación o las prioridades del habitante.

\section{EL JUEGO DEL PODER SOBRE LA ESTÉTICA DE LA VIVIENDA}

La tensión triangular entre "estética del arquitecto", estética de la "opinión pública” o del "sentido común" (en los hechos solo la del sentido común de los sectores socialmente consolidados) y "estética del habitante" (en particular cuando proviene de sectores en situación de exclusión) se presenta en cualquier modelo de gestión habitacional pero se resuelve de distintas formas según la distribución de poder entre esos actores, propia de cada modelo. En la gestión convencional de vivienda social (terminada, llave en mano, adjudicada por puntaje a habitantes desconocidos) el conflicto entre las concepciones estéticas del arquitecto y las del habitante se pone en evidencia y toma la dimensión correspondiente a cada caso recién a partir del momento en que éste recibe su vivienda, y la conoce por primera vez y, cuando el conflicto se produce y tiene un cierto peso, se resuelve sólo parcialmente con las modificaciones que logra introducirle, muchas veces contra los reglamentos y las normas, o simplemente se expresa en el estado de malestar y desagrado de los habitantes, o deriva hacia un conflicto.

El tema en discusión aquí no es tanto la esencia de la bella forma, o de la expresión formal, como la definición de cuál es la bella forma legítima en cada caso concreto, y quién la produce o la selecciona, y con qué fines. También, quién disfruta y quién padece, y cómo, los resultados de todo esto. Y finalmente, y sobre todo, lo que se enfoca aquí es la inciden- 


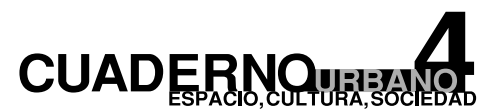

190

La Casa Bella. Estética, Identidad, Poder y Distorsión de Metas en la Vivienda Social

5- Traigo como referencia la

legislación británica, que hace obligatoria en determinados distritos la aprobación por los vecinos de cualquier proyecto de vivienda nueva a construir, con especial atención sobre la relación de su propuesta estética con las de las construcciones de todoel vecindario inmediato, como paso formal y obligado para su aprobación municipal. cia que la buena o mala resolución de este juego de poder en torno a la propiedad de la bella forma puede tener sobre la calidad de la vivienda, evaluada, sobre todo, en su capacidad de responder en positivo a las necesidades genuinas del habitante, y también en su capacidad de contribuir positivamente a la conformación del paisaje. Buscando conciliar, claro, la satisfacción de estos dos objetivos.

\section{LA DISTRIBUCIÓN DEL PODER DE DECISIÓN EN LOS DIVERSOS ESQUEMAS DE PRODUCCIÓN DE LA VIVIENDA Y LA CUOTA DEL USUARIO EN CADA UNO DE} $\underline{\text { ELLOS }}$

En la práctica profesional más amplia y corriente en países donde rige, en versión más o menos rigurosa o lograda, la economía de mercado, los principales candidatos a compartir la autoría del proyecto arquitectónico con el arquitecto son el comitente y el usuario, que en algunos casos pueden ser la misma persona. En otros casos los tres personajes son la misma persona, y en otros son tres actores diferentes en un triángulo en fuerte tensión, a los que en determinados contextos institucionales o culturales se agregan otros con su propio potencial de incidencia en las decisiones: el municipio con sus normas y su poder de policía y los vecinos inmediatos, por ejemplo, aunque este último mecanismo no funciona en Argentina o en América latina con la finalidad ni con la precisión con que se presenta en otras sociedades 5 . O los jurados (arquitectos) de concursos, cuyo dictamen suele anteponerse a la opinión del comitente y por cierto prescindir de la del usuario real.

En la práctica corriente se manejan distintos esquemas de relación de poder entre los tres actores principales, acompañados ocasionalmente de algunos de los otros. Los esquemas posibles son más numerosos que éstos. Aquí me limito a los más frecuentes, con especial atención al papel que le cabe al usuario en la definición del lugar donde le va a tocar vivir.

1 EL PODER DEL USUARIO-COMITENTE: La situación más típica en que el usuario puede introducir sus propias pautas y preferencias estéticas es aquella en que comitente y usuario son la misma persona, frente a un arquitecto contratado con esa 


\section{Víctor Saúl Pelli}

La Casa Bella. Estética, Identidad, Poder y Distorsión de Metas en la Vivienda Social

condición. En realidad el poder de decisión le viene al usuario no tanto de ser usuario como de ser comitente, es decir que ese poder está entre las atribuciones del que paga. Este esquema se reproduce en algunos programas estatales de vivienda social que, en sintonía con el esquema de mercado, otorgan créditos o subsidios a la demanda, es decir al habitante, que con este refuerzo puede actuar como comitente frente al arquitecto y mantener algún control (parcialmente limitado por las normas del crédito) sobre el producto, incluyendo su estética.

2 ELPODERDEL USUARIO-COMPRADOR: El esquema del mercado de viviendas terminadas ofrece al usuario la posibilidad de hacer valer su criterio por la vía del derecho a elegir que le otorga el sistema de mercado, aún con las distorsiones y limitaciones de este esquema de libre elección que se señalan más adelante. El arquitecto y su comitente (no usuario) producen viviendas para venta o alquiler, y el usuario-comprador es libre de decidir, como con otros bienes (autos, vestimenta, muebles, artefactos), comprando o pasando de largo. El arquitecto y el comitenteinversor también pueden decidirse a volcar sus propias preferencias estéticas en lo que producen para vender, apostando a una buena recepción por parte de los consumidores, o pueden hacer ensayos de riesgo a partir de conjeturas más o menos sistemáticas sobre las preferencias del comprador-usuario potencial ${ }^{6}$. Aparte de esto, y como una limitación e incluso una distorsión, el juego incluye otros ingredientes propios de la dinámica del mercado en cualquier rubro de consumo, como la manipulación y persuasión a través de la promoción publicitaria o financiera, o el uso de una estética superficialmente seductora, de mercadeo, que no es ni la del arquitecto ni la del usuario pero que está dirigida a provocar apetencias, como con cualquier otro producto de consumo en oferta. El mecanismo "puro" de mercado también se debilita en las situaciones de insuficiente calidad y variedad de oferta dentro de un mercado local poco dinámico o creativo, o monopolizado, que obligan al comprador-usuario a optar por la única calidad de oferta disponible, aunque no le guste. Dentro de estas limitaciones, debe reconocerse que el juego de mercado deja al habitante-comprador o inquilino potenciales, en buena medida, y con la excep-
6-El suplemento "Diario de Arquitectura" del diario Clarín, Buenos Aires, 22 septiembre 2003 , ofrece un ejemplo llamativo de este esquema de trabajo: Una empresa inmobiliaria desarrolla, con un estudio de arquitectura, una propuesta para el mercado de vivienda de alto costo, con una torre de 14 pisos en lo que la publicación identifica como "estilo francés". Segúnel artículo, la oferta recibió una amplia aceptación, con reservas concretas de compra. Lo que el artículo-y otros posteriores-señalan como digno de atención es que el mismo comitente, en otro rol, con los mismos arquitectos, seleccionados por concurso, habían producido antes un edificio para museo público de tendencias formales decididamente contemporáneas con reconocimiento público y del gremio de los arquitectos por su calidad de diseño. La decisión sobre las características formales del nuevo edificio de vivienda en este caso es una muestra de adecuación del equipo comitentearquitecto al juego de la oferta y la demanda, "apostando", por lo visto con éxito (de ventas, que es el sentido en que en el mercado se contabiliza el éxito), a una determinada percepción de las tendencias de consumo para edificios de ese costo y esa ubicación urbana. La "oferta" parecellenar expectativas en cuanto a lo que "el potencial usuario-comprador piensa que él 


\section{CUADERNQ}

192

La Casa Bella. Estética, Identidad, Poder y Distorsión de Metas en la Vivienda Social

es", y en cuanto a "lo que quiere que los demás piensen quééles", es decir, en cuanto a afirmación de una determinada identidad, auténtica o pretendida. Sibien los arquitectos tendrán que recomponer su prestigio frente a los colegas y críticos defensores del rigorestilístico y disciplinar, este trabajo no puede dejar de verse como un caso interesante de búsqueda de la satisfacción de las necesidades habitacionales como las siente el habitante, es decir de búsqueda de la "buena vivienda". Aparte de la búsqueda del buen negocio, que es otro tema.

7-CATENAZZI,A.y BOSELLI,T 1997 (1999). ción de este último caso, la libertad de elegir y descartar que, cabe recordarlo, está absolutamente ausente de la mayor parte, si no en la totalidad, de los mecanismos convencionales de adjudicación en la vivienda social. No es poco, aún con las limitaciones y perversiones usuales. De todos modos, conviene no olvidar que aquí también la condición para que el usuario ejerza su derecho y su poder de decisión es que tenga dinero suficiente y esté dispuesto a gastarlo.

3 EL USUARIO FORZADAMENTE PASIVO DE LA VIVIENDA DE ACCIÓN INSTITUCIONAL Y SUS MODOS DE EXPRESIÓN: Ya se señaló que en la vivienda producida desde el Estado, en su forma más convencional de gestión hasta ahora, la posibilidad de incidencia del usuario en la calidad de la respuesta a sus necesidades habitacionales a través de su participación o de su libre elección, no existe². De hecho, en la vivienda pública de llave en mano adjudicada por sorteo existe una instancia sombría de algo que puede verse como participación cuando de alguna manera los habitantes expresan su insatisfacción de vivir en un edificio en cuya concepción no han participado y que no han elegido, y que les resulta poco o nada tolerable -aunque es cierto que en la mayoría de los casos no sólo por insatisfacción estética. En esas situaciones los habitantes expresan su incomodidad a través de por lo menos cuatro vías: la alteración, autorizada o no, de las características formales y funcionales de su vivienda, que puede ser un sector de un edificio colectivo; el uso indebido y destructivo de espacios, componentes e instalaciones propios y comunes; la generación y padecimiento de problemas de salud física o mental; y el conflicto social: situaciones de violencia y agresión recíproca y hacia extraños. Vale la pena señalar que los principales perjudicados por estas formas de expresión de insatisfacción, al menos las tres últimas, son los mismos usuarios. Sólo indirectamente, y ocasionalmente, son perjudicados el arquitecto, en su prestigio, o en la pureza de la imagen de su obra; o la institución comitente, generalmente el Estado, o sus administradores del momento, en la conmoción social que se genera, con malos réditos políticos. 


\section{Víctor Saúl Pelli}

La Casa Bella. Estética, Identidad, Poder y Distorsión de Metas en la Vivienda Social

\section{TRES ESQUEMAS DE DISTORSIÓN O INSUFICIENTE APLICACIÓN DEL CONCEP- TO DE PARTICIPACIÓN}

4 LA ILUSORIA ARQUITECTURA PARTICIPATIVA: Este es un esquema de mucho menor difusión y frecuencia, y casi nulo en Argentina en particular, pero vale la pena examinarlo como un buen ejemplo de distorsión de una idea. Hay un tipo de arquitectura presentada como "de participación", que se desarrolla con sistemas constructivos de elementos diseñados por el arquitecto y combinables según el criterio del usuario pero dentro de las reglas del juego combinatorio diseñado por el arquitecto. En este caso la voluntad y el estilo formales del arquitecto, supuestamente sometidos a los criterios del usuario, afloran claramente en el resultado del juego combinatorio. Si bien es dudosa la supuesta "puesta en plano de igualdad, en el campo estético, del arquitecto, en relación con los criterios del habitante", con que solían presentarse estos experimentos, es de justicia señalar, a efectos de lo que se propone este trabajo, que el juego formal del arquitecto no produce aquí un corte absoluto entre la solución habitacional resultante y las necesidades y expectativas del habitante, que al menos puede obtener alguna satisfacción formal y funcional acomodando a su gusto las piezas del juego ${ }^{8}$.

\section{LA REPRESENTACIÓN (NO OTORGADA) DEL USUARIO POR EL ARQUITECTO} CONDESCENDIENTE: En este esquema, que apareció con bastante recurrencia en el panorama argentino de los concursos de conjuntos habitacionales de acción social de los anos '70, el arquitecto asume por propia decisión el papel de representante del usuario, a través de su interpretación de lo que es la "cultura del habitante", o la "cultura popular" con su componente estético, inspirándose en imágenes idealizadas, y adecuadas a las normas del concurso, de lo que el arquitecto imagina que es la "vivienda popular". Aquí no sería justo entrar en la crítica de la arquitectura resultante ni de los autores, sino en la crítica del modelo de gestión, que no coloca al profesional en el compromiso y en la situación de entrar en diálogo real con los usua-

\footnotetext{
8- Un exponente de esta tendencia fueron las obras de Ralf Erskine, en los años 70. "BykerWall, Newcastle, 1974, es un ejemplo de participación pública en el diseño, sinembargo el resultado presenta una fuerte semejanza con otros edificios de Erskine. Podría ser leído como lo que Erskine quería hacer a pesar de la participación pública. Pero la real participación es un diálogo en el que una parte propone ideas sobre las que los otros comentan. Esto ocurrió ciertamente en el caso de Byker, por lo tanto se trata después de todo de un caso de verdadera participación" Geoffrey Broadbent: "El lenguaje de la arquitectura post-moderna. Un resumen", en Architectural Design, Vol 4, nº41, 1977. pág. 268. (la traducción del párrafo es de V.S.Pelli). Sibien no coincido con la vagamente irónica definición de participación que da Broadbent en este texto, el caso puede tomarse como representativo de las tendencias de "arquitectura participativa" cultivadas en los años "70 en los países centrales.
} 


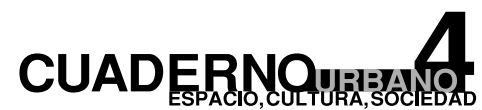

194

La Casa Bella. Estética, Identidad, Poder y Distorsión de Metas en la Vivienda Social

rios concretos, "con nombre y apellido", con "rostro y palabra" y con gustos propios, que sin duda le pueden transmitir, más o menos desordenadamente, datos reveladores y probablemente inesperados sobre lo que es su real imagen de la vivienda de sus sueños y de sus necesidades, la verdadera vivienda popular. Por otra parte, la deformación estructural propia de los modelos de gestión convencionales hace que la mayoría de esas casas de diseño bien intencionado pero mal encaminado terminen en manos de familias que social y económicamente están por encima del habitante originalmente supuesto, de manera que se encuentran viviendo en un remedo de vivienda popular muy lejano de sus propios gustos y sobre todo de sus aspiraciones de identificación social, aspiraciones que terminan satisfaciéndose con costosas remodelaciones.

\section{LA PARTICIPACIÓN SUBORDINADA DEL USUARIO EN LOS ESQUEMAS CONVEN-} CIONALMENTE DENOMINADOS "AYUDA MUTUA". En estos esquemas "las instituciones (generalmente pero no exclusivamente el Estado) se hacen cargo de la solución habitacional, organizándola con el criterio de inclusión de los propios habitantes exclusivamente como mano de obra en la ejecución de las obras físicas y reservando para la institución y sus funcionarios y técnicos la definición del problema, la definición de los satisfactores adecuados (listado de requerimientos funcionales, emplazamiento urbano, diseño urbano, diseño arquitectónico), la organización y dirección de los procesos de gestión y resolución, la administración de los fondos destinados a la financiación de los procesos". Hay que reconocer que hay poco aquí de participación y menos de autogestión, y sobre todo hay poco de ruptura del esquema vertical de asistencia paternalista, que incluye la decisión total sobre formas y estilos a cargo de la institución promotora y de sus representantes. Todo esto sin entrar en la ya histórica polémica en torno al empleo de la mano de obra del propio habitante. Pero conviene por otro lado reconocer que hay un cierto avance en relación con los modelos más convencionales de vivienda terminada, llave en mano, etc.: aquí el conjunto de usuarios está definido antes de encarar el proyecto y tiene alguna oportunidad de entrar en contacto con los respon- 


\section{Víctor Saúl Pelli}

La Casa Bella. Estética, Identidad, Poder y Distorsión de Metas en la Vivienda Social

sables de las decisiones, y de familiarizarse con su casa mientras se está gestando y construyendo. Hasta es posible, sin modificar la esencia del esquema, introducirle una etapa inicial participativa en la que los usuarios sean incluidos en la discusión y concepción del proyecto arquitectónico de una casa-tipo, con sus variantes tipológicas de adecuación a diferentes demandas o condicionantes (número de dormitorios y baños, situaciones en esquina o de final de tira o entre medianeras, etc.) que se construirá para todos, sin definición de destinatario, y luego se sorteará. Si bien no hay espacio para que cada familia defina la conformación de su vivienda ni las prioridades de satisfacción (pues dentro del esquema estándar para este modelo de gestión nadie sabrá hasta el final cual es su casa, que se adjudicará por sorteo o por méritos en su trabajo de obra), se puede reconocer aquí un cierto, reducido, grado de participación, que puede conducir a algún grado de mejor nivel de satisfacción durante el uso de la vivienda.

\section{AFIRMACIÓN DEL DERECHO DEL HABITANTE A SER PARTÍCIPE DIRECTO DE LA DEFINICIÓN DE SU VIVIENDA, INCLUYENDO LA DEFINICIÓN ESTÉTICA}

Se espera que el conjunto de estas muestras logre ser lo suficientemente expresivo como para permitir afirmar que este juego de poder es uno de los puntos clave para el buen o mal encaminamiento de una estrategia de gestión social de vivienda, pues esta definición, en cada caso y en cada modelo, determina qué tipo de satisfacciones y beneficios le corresponde obtener a cada uno de los actores del proceso de resolución, más gobernado de lo que generalmente se admite por las convicciones estéticas de cada actor y por el uso que cada uno de ellos hace de esta vía de expresión. Si se acepta que la definición de un modelo correcto de gestión habitacional debe apuntar a la satisfacción de las necesidades genuinas de la gente ${ }^{10}$, se hace indispensable afirmar el derecho del habitante concreto e individual a ser partícipe, con una amplia cuota de poder de decisión, en la definición general de su vivienda y, en lo que hace al tema de este trabajo, en la definición estética, no sólo la definición de los códigos estéticos (signos y estilos), sino también, y más importante, la de la prio- $\overline{10-\text { PELLI, V.S. (2002). }}$ 


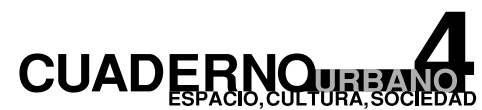

196

La Casa Bella. Estética, Identidad, Poder y Distorsión de Metas en la Vivienda Social

ridad que el logro del "efecto" estético debe tener en la aplicación de los recursos financieros que se destinan a su vivienda. Debe tener derecho, en una situación de escasez de fondos, a participar activamente en la decisión sobre la incorporación o el descarte de efectos de impacto estético o de identificación, en particular los que no son de su interés, y que impliquen gastos extra.

La satisfacción de ese derecho es una exigencia de tal envergadura que demanda una revisión de los modelos de gestión (y de los encuadres teórico-conceptuales sobre acción social en general), en vigencia, que en su estructura actual no le dan cabida.

De todos modos este todavía no es el eje de este trabajo.

\section{LOS MODELOS DE GESTIÓN PARA LA ACCIÓN SOCIAL DE VIVIENDA QUE OTOR- GAN PODER DE DECISIÓN AL HABITANTE}

En este trabajo se darán por conocidos los modelos ya probados y perfeccionados de gestión habitacional que reconocen ese derecho y otorgan, de manera sistemática, poder de decisión al habitante sobre la conformación y la gestión integral de su solución habitacional. Me limitaré aquí a recordar el perfil general de estos esquemas citando sus consignas más significativas:

11- Una versión más ajustada de esta consigna se desarrolla en PELLI, V.S

(2003).
* Resolución de las necesidades habitacionales básicas para el número más extenso posible de personas como meta prioritariall .

* Progresividad de la solución.

* Participación activa y estructurada del habitante en la gestión integral de la concepción y producción de la solución habitacional, dentro de un esquema general de concertación de los principales actores involucrados en la gestión habitacional. 


\section{Víctor Saúl Pelli}

La Casa Bella. Estética, Identidad, Poder y Distorsión de Metas en la Vivienda Social

La aplicación de estos modelos, con estas consignas, requiere reformas de fondo en la organización y en la práctica de las acciones de producción de vivienda. En este trabajo, enfocado sobre el juego de poder que tiene como tema la expresión estética, merecen especial atención los desafíos que debe enfrentar y los compromisos que debe asumir el actor que por definición tiene en sus manos la mayor parte de los recursos, las herramientas y, en los modelos de gestión convencionales, las atribuciones de resolución de este juego.

\section{EL ARQUITECTO EN LOS MODELOS DE GESTIÓN DE NECESIDADES BÁSICAS, PROGRESIVIDAD Y PARTICIPACIÓN.}

De hecho hay muchos arquitectos trabajando en el marco de estos modelos, en toda la extensión de la América latina en particular y, en términos más generales, en gran parte de los países periféricos y también de los países centrales. Trabajando en firme: no se trata de trabajo voluntario de horas libres dedicadas a una actividad solidaria, sino de una opción de carrera profesional, plena y rentada, y de un particular modo de vida y de realización.

Estos arquitectos dejan de lado (al menos mientras trabajan en este campo) los modos, motivaciones, códigos y metas personales predominantes en las formas más convencionales de ejercicio de la profesión, entre ellos el papel dominante que juega el manejo de la expresión formal, en la medida en que profundizan su compromiso con una forma específica de encarar y ejercer la profesión. Pero es importante dejar claro que no les hace falta, ni es recomendable que lo hagan, renunciar a su formación de creadores entrenados para lograr calidad estética en el espacio habitable, ni tampoco al placer que les produce ejercitarla. Lo que hace la diferencia es la puesta de sus habilidades al servicio de una tarea creadora que valorice las expectativas y deseos de los habitantes concretos.

No voy aquí, entonces, a delinear un perfil teórico de profesional y de actividad profesional, sino a registrar una forma de trabajo ya consolidada en la práctica y muchas veces transitada. 


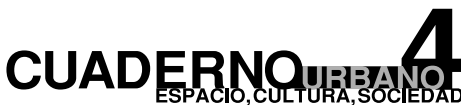

La Casa Bella. Estética, Identidad, Poder y Distorsión de Metas en la Vivienda Social

Visto desde el ángulo explorado en este trabajo, de lo que se trata es de propiciar modelos de gestión que le permitan al arquitecto y al habitante protagonista de planes de vivienda social, entrar en una relación por lo menos equivalente a la del trato entre arquitectos y comitentes-usuarios con mayor capacidad de pago, en la práctica convencional de mercado de servicios profesionales. Aunque no igual, pues aquí se trata de trabajo consensuado en mesas de coordinación intersectorial, no necesariamente regido por las condiciones de pago del servicio, como en aquél caso. La pregunta probable es: ¿cómo se hace esto en programas masivos? Este es uno de los temas clave en el debate generado por las consignas de participación, y su respuesta es tema central de investigación y experimentación. En otro trabajo (Pelli, 1992) señalé que un problema masivo, como es el de la vivienda para la población en situación de pobreza en América latina, merece programas masivos, no necesariamente integrado por proyectos masivos. Un programa masivo puede estructurarse en células de trabajo (allí cito como referencia la estructura del sistema educativo, organizado en células de entre 15 y 40 alumnos por docente) cuya escala relativamente reducida permita el trato persona a persona entre el habitante individual y el equipo técnico. Por cierto que esto apunta a una concepción de la solución habitacional fuertemente diferente de las que nos tienen habituados, pero este no parece ser un obstáculo insalvable, si se aprecian los beneficios de este abordaje. Dentro de un esquema de organización que permita al arquitecto trabajar de este modo con la gente, éste puede aportar su calificación y destreza para el juego con las formas y sus significados, en asociación con el habitante, escuchando, entendiendo, admitiendo, explicando, respetando, discutiendo e intercambiando gustos y preferencias, e incluso ganándose lícitamente su confianza. En esas condiciones el habitante suele estar dispuesto a permitir (ceder poder; ceder parte del poder recientemente recuperado o adquirido en virtud de la aplicación de consignas de participación) e incluso a invitar al arquitecto a introducir sus habilidades y gustos. Pero por supuesto, él, el habitante, se queda por ahí cerca para poner límites a los sueños o intereses demasiado personales del arquitecto y para incluir sus propios sueños e intereses: es su casa. Pero también es frecuente que, siempre a la vista del presupuesto, termine dejando, como ya se señaló, los refinamientos estéticos, simbólicos y de confort para más adelante y dándole unos 


\section{Víctor Saúl Pelli}

La Casa Bella. Estética, Identidad, Poder y Distorsión de Metas en la Vivienda Social

metros cuadrados más a los dormitorios, o dejando una losa preparada para una futura planta alta, con los correspondientes hierros de columnas a la vista, aunque la casa quede en una primera instancia "sin terminar" (por ejemplo sin revocar y/o pintar, o sin cielorraso, o sin algún parapeto "decorativo" que oculte esos hierros) y poco presentable. Lo bueno es que una vez que el arquitecto aprende a entrar en el juego, este trabajo, que seguramente no le dará las satisfacciones propias del ejercicio más convencional de la profesión, con sus ingredientes de exhibición y competencia, no es vivido por él como un esforzado sacrificio a la solidaridad, sino como un sofisticado desafío a su oficio de creador y, si llega a lograr resultados que lo satisfagan a él tanto como al habitante, como un éxito (en otra clave que las más habituales en la profesión) y una especial fuente de gratificación. El trabajo así es una oportunidad para la búsqueda y la innovación "en clave popular y equitativa”, si se quiere llamarla así.

Mientras no se produzca una situación de trabajo como ésta, los fuertes condicionamientos, reflejos y compromisos habituales en la profesión, que por lo general ponen al arquitecto en actitud de llevar demasiada agua (agua que en rigor es del habitante) para esos molinos, lo colocarán también, al encontrarse con obstáculos serios, propios de las estrategias de economía básica, progresividad de la solución y participación activa del habitante con sus propias exigencias, en la posición de obstaculizador o distorsionador de procesos y productos, o lo apartarán, y apartarán su talento, de este tipo de tareas.

Ésta es la mayor de las preocupaciones que dan origen a este trabajo, si bien no la única, pues, como se vio, también merece atención la presión que ejercen otros actores (no precisamente los habitantes) para imponer sus propios criterios estéticos sobre la solución habitacional. 


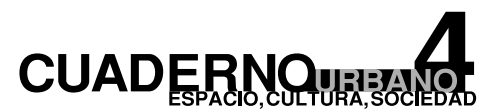

La Casa Bella. Estética, Identidad, Poder y Distorsión de Metas en la Vivienda Social

\section{LA CONSTRUCCIÓN DE LA EQUIDAD EN LAS DECISIONES SOBRE LA CALIDAD DE LA VIVIENDA}

La estética, seguramente no hace falta decirlo, es sólo una de las categorías en juego en la confrontación que tiene por objeto el manejo de las decisiones sobre las características y la conformación de la vivienda y de la gestión habitacional. No es la principal pero está lejos de ser la menor. No se trata tanto, en este plano de conflicto, de reivindicar el derecho del habitante a participar activamente de las decisiones y del manejo de lo que se entiende por belleza en la concepción de la casa que va a ser su casa, como de señalar la necesidad de introducir importantes modificaciones en los mecanismos de gestión que abran camino a las posibilidades del habitante de ejercer ese derecho, a través de instancias de trabajo grupal y transectorial. Esto requiere, por cierto, entre otros requisitos, un estado de convicción íntima de los arquitectos y de los otros actores con poder de decisión al conceder ese derecho al habitante. Estos requisitos, más allá de sus implicancias conceptuales y motivacionales, implican también una particular orientación de la gestión institucional de la solución habitacional: Convicción y fuerza política en los funcionarios a cargo de las decisiones básicas; formación de cuadros de personal preparados técnicamente y motivados éticamente para esta forma de trabajo; programación de trabajos con disponibilidad de tiempo real adecuada a las necesidades del diálogo, de la discusión, de la concertación y de la negociación como herramientas y modos de trabajo, y disponibilidad real de presupuesto para financiar este tiempo y estas actividades, con estos actores. Esto es, generar el escenario, disponer los actores adecuados, darles tiempo, consignas y estímulo para que entren en buena resonancia entre ellos, y valorizar el "espectáculo" resultante, en este caso, no desde las expectativas del espectador sino desde las del actor principal, el habitante.

La estética de los habitantes del sector popular suele, salvo excepciones, tener expresiones y proyecciones modestas, aunque no menos valiosas que las de la estética más trascendente del arquitecto-artista profesional: no es difícil servirla, si uno se decide a conocerla, valorarla y respetarla. Tampoco es difícil avasallarla, imponiendo la estética de uno, pues 


\section{Víctor Saúl Pelli}

La Casa Bella. Estética, Identidad, Poder y Distorsión de Metas en la Vivienda Social

suelen ser ciudadanos con escaso poder individual de discusión y acostumbrados a saber cuándo no hay otra alternativa que someterse. Lo difícil es decidirse a quitar de las primeras filas de la escena la estética de uno (suponiendo que "uno" es el arquitecto, o el profesional en general, o el funcionario, o el ciudadano con poder), que es casi lo mismo que decir: quitarse uno mismo de las primeras filas de la escena, o más precisamente quedarse pero compartir las primeras filas. Aquí se trata de disponerse a ver en primera fila a la gente, y explorar fusiones enriquecedoras para todas las partes. Si hablamos de algo más que de construir casas y pensamos que la acción de vivienda es una de las oportunidades fuertes para el desarrollo de la capacidad de desempeño ciudadano democrático de la gente mediante la cesión de espacios que les permitan hacer valer sus intereses, lo que, dicho de otra manera, es una de las oportunidades fuertes para contribuir a la eliminación de su situación de exclusión, este acto de cesión de espacios y sobre todo de diálogo y acción creadora compartida aparece como un objetivo central de la estrategia habitacional y como una oportunidad para la auténtica satisfacción de las necesidades habitacionales.

\section{$\underline{\text { BIBLIOGRAFÍA }}$}

BALISTA, José. 1984.- Renovación urbana y villa miseria. Ediciones Tres Tiempos, S.R.L. Buenos Aires, Argentina. ISBN $950-18-055-6$.

BARRETO, Miguel Ángel. 2000.- La imagen de la vivienda. Una antropología de las formas urbanas de la ciudad de Posadas. Editorial de la Universidad Nacional de Misiones. Posadas, Misiones, Argentina.

BASS, Stephen; DALAL-CLAYTON, Barry; PRETTY, Jules. 1995. Participation in strategies for sustainable development. (London, United Kingdom. Environmental Planning Issues, N 7, May. Environmental Planning Group. International Institute for Environment and Development).

BOUDON, Philippe. "Pesac, el barrio de Le Corbusier". 1959.- Ediciones Dunod, París, Francia. Citado por Henri Lefebvre en De lo rural a lo urbano. Ediciones Península, Barcelona, España, 1971. Original Du rural àl'urbain. Ediciones Anthropos, París, Francia, 1970.

CATENAZZI, Andrea y BOSELLI, Teresa. 1999.- "Los arquitectos proyectistas y las políticas oficiales de Vivienda: Área metropolitana de Buenos Aires 1963" - 1973. Artículo en Revista AREA, de la Facultad de Arquitectura, Diseño y Urbanismo de la UBA. № 5, agosto 1997 (1999) Págs. 35 a 53. ISSN 0328-1337.

MAX NEEF, ELIZALDE y OPENHAYN. 1986.- Desarrollo a escala humana. Chile: CEPAUR y Suecia: Fundación Dag Hammarskjold. 


\section{CUADERNA}

La Casa Bella. Estética, Identidad, Poder y Distorsión de Metas en la Vivienda Social

PELLI, Víctor Saúl. 1992.- “Clarificación y Replicabilidad. La aplicación masiva de los proyectos progresivos y participativos de vivienda. Encrucijada de los grupos de trabajo en vivienda progresiva y participativa en América Latina en la última década del siglo XX". - Edición IIDVi, Instituto de Investigación y Desarrollo en Vivienda, Facultad de Arquitectura y Urbanismo, Universidad Nacional del Nordeste..- Este artículo ha sido reproducido en otras publicaciones.

PELLI, Víctor Saúl, con la colaboración de GIRÓ, M.; FRANCO, R.; PELLI, M. B.: ALCALÁ, L. 2000.- "La asignatura «Gestión y Desarrollo de la Vivienda Popular»: formación para el abordaje de la pobreza habitacional en la Carrera de Arquitectura"; ponencia en el VI Encuentro de la Red Universitaria de Cátedras Latinoamericanas de Vivienda. Córdoba, Argentina, Octubre.

PELLI, Víctor Saúl, 2001.- "Autoconstrucción, las tres versiones”. Artículo en la revista "Vivienda Popular”, editada por la Facultad de Arquitectura de la Universidad de la República Oriental del Uruguay, n 8, Abril, (siete páginas).

PELLI, Víctor Saúl (2002): "La necesidad como basamento técnico y político de la gestión habitacional" Evaluado y aceptado para su publicación en la revista Área, de la Facultad de Arquitectura, Diseño y Urbanismo de la UBA. Original de 15 páginas, 42.000 caracteres incluyendo espacios. Escrito y aceptado en 2002.

PELLI, Víctor Saúl. 2003. "Estrategias habitacionales de saturación de soluciones básicas." Publicado como "Análisis Metodológico de Estrategias habitacionales de saturación de Soluciones Básicas." INVI, revista del Instituto de la Vivienda de la Facultad de Arquitectura y Urbanismo de la Universidad de Chile, Santiago, Chile, № 48, Diciembre. ISSN 0716 - 5668. (Págs. 113 a 135).

RAMÍREZ, Ronaldo, 2001.- "Notas sobre medio siglo de políticas de vivienda”. Revista "Vivienda Popular", n9, Setiembre 2001, Montevideo Uruguay.

TURNER, John F.C., 1977 (1ª edición en español) "Vivienda, todo el poder para los usuarios". Herman Blume Ediciones, Madrid, España. ISBN $84-7214-124$ - 1. Título original "Housing by people. towards autonomy in building environments", Marion Boyars Publishers. London, 1976. 